\title{
AREA-WIDE MANAGEMENT OF INVADING GYPSY MOTH (Lymantria dispar) POPULATIONS IN THE USA
}

\author{
A. M. LIEBHOLD ${ }^{1}$, D. LEONARD ${ }^{2}$, J. L. MARRA ${ }^{3}$ AND \\ S. E. PFISTER ${ }^{4}$ \\ ${ }^{1}$ USDA Forest Service Northern Research Station, Morgantown, West Virginia \\ 26505 USA; aliebhold@fs.fed.us \\ ${ }^{2}$ USDA Forest Service, Forest Health Protection, Asheville, North Carolina 28802, \\ USA \\ ${ }^{3}$ Washington State Department of Agriculture, Olympia, Washington 98504, USA \\ ${ }^{4}$ USDA/APHIS/PPQ/CPHST, Buzzards Bay, Massachusetts 02542, USA
}

\begin{abstract}
SUMMARY
The European strain of the gypsy moth, Lymantria dispar L. (Lepidoptera: Erebidae) was accidentally introduced to North America over 100 years ago and despite its explosive population growth there, the species still only occupies less than $1 / 3$ of its potential range. While this slow rate of spread can be attributed in part to the limited dispersal capacities of this strain, its constrained distribution mainly reflects the success of efforts to limit range expansion of this species. Currently, two major area-wide programmes are operated to limit the spread of the gypsy moth in the USA, in addition to a third programme that suppresses gypsy moth outbreaks in the infested areas. The detection / eradication programme is led by the United States Department of Agriculture - Animal and Plant Health Inspection Service (USDA-APHIS) in cooperation with state governments and utilizes networks of pheromone traps to detect newly invaded populations of the gypsy moth in the uninfested portions of the USA. Over the last decades, hundreds of isolated populations have been detected and eradicated. Most eradication treatments in the USA are conducted using aerial sprays of Bacillus thuringiensis. The USDA Forest Service also operates another area-wide programme entitled "Slow the Spread" (STS) in cooperation with state agencies that operates at the edge of the generally infested area and aims to slow the gypsy moth's spread. This programme also uses grids of pheromone traps to locate isolated populations, which are then treated. The STS programme has adopted several major innovations that make it one of the most advanced area-wide programmes for managing invading species. Among these innovations, the STS programme adopts a complex geographic information system (GIS)-based decision algorithm for processing trap data, identifying treatment areas and evaluating programme efficacy. Also, the STS programme is unique in that it largely has adopted mating disruption to eradicate or suppress isolated populations ahead of the invading front.
\end{abstract}

Key Words: Lepidoptera: Erebidae, eradication, barrier zone, biological invasion, decision support

J. Hendrichs, R. Pereira and M. J. B. Vreysen (eds.), Area-Wide Integrated Pest Management: Development and Field Application, pp. 551-560. CRC Press, Boca Raton, Florida, USA. (c) 2021 U. S. Government 


\section{INTRODUCTION}

While many invasive species are rare in their native ranges, this is not the case for the gypsy moth Lymantria dispar L. (Lepidoptera: Erebidae). Across much of its native range, which spans most of temperate Asia, Europe and North Africa, this species episodically reaches outbreak levels, causing massive defoliation of host trees (Giese and Schneider 1979; Johnson et al. 2005). Similarly, across much of the region that the gypsy moth has invaded in North America it has caused considerable damage, i.e. $>15$ million ha have been defoliated in the USA during the last 30 years alone (USDA/USFS 2017). Forest defoliation caused by the gypsy moth can have severe impacts that include effects on aesthetics, particularly in forested residential areas, as well as triggering tree mortality and growth loss, ultimately leading to shifts in regional forest composition (Morin and Liebhold 2016).

The history of gypsy moth invasion in North America began in 1868-1869 when Étienne Léopold Trouvelot accidentally released the insect in the backyard of his house in Medford, Massachusetts (Liebhold et al. 1989; McManus 2007). At the time, Trouvelot was a commercial artist but had an amateur interest in entomology and was rearing a large assortment of insects in his garden. Though Trouvelot notified local authorities about the escaped insects, no action was taken until about 1880 when the first outbreak started in his neighbourhood, alarming residents. At that time, the state of Massachusetts embarked on a large eradication campaign, but the effort was abandoned in 1900 as a result of the lack of effective surveillance and control tools. Nevertheless, this programme was apparently the first attempted insect eradication in the world. Even though the gypsy moth has been in North America for almost 150 years, it still only occupies less than 1/3 of its potential range (Fig. 1) (Morin et al. 2004). One of the causes of this exceptionally slow invasion spread is that in the European strain of the gypsy moth, from which populations were introduced, females are incapable of flight and most spread is driven by accidental movement of life stages by humans (Liebhold et al. 1992). The other reason why spread has been so slow is that efforts to limit its spread have been successful. Even though the initial eradication campaign in Massachusetts was a failure, there have been numerous government-led barrier zones and other programmes aimed to contain this insect; these efforts have evolved over the last century, but the programmes currently in place represent stateof-the-art area-wide management and serve as excellent models for potential application to other insect invasions.

Currently there are three different large programmes that target gypsy moth populations in the USA and these programmes vary both in their objectives and in their geographic scope (Fig. 1). First, United States Department of Agriculture (USDA) Forest Service, Forest Health Protection works with various state agencies to manage the Gypsy Moth Cooperative Suppression Programme. This programme operates within the gypsy moth generally infested area to suppress outbreak populations of the gypsy moth; because decisions about treatments are made individually on a stand-by-stand basis, this cannot be considered a true area-wide management programme.

The second programme, the gypsy moth detection/eradication programme is led by USDA Animal and Plant Health Inspection Service (APHIS) Plant Protection and Quarantine (PPQ) works with state agencies and aims to exclude gypsy moth invasion 
in regions of the USA where the gypsy moth is not currently established. The third programme, the gypsy moth "Slow the Spread" (STS) programme is carried out by the USDA Forest Service in cooperation with state agencies and operates in the transition area between the infested and uninfested portions of the USA. The objective of this programme is to slow the gypsy moth's spread into the uninfested region. Both, the detection/eradication and the STS programmes are examples of area-wide management. These programmes represent the culmination of an evolution of technology and strategy and thus serve as model programmes for other area-wide efforts. Here we describe both programmes, including both strategic and methodological details.

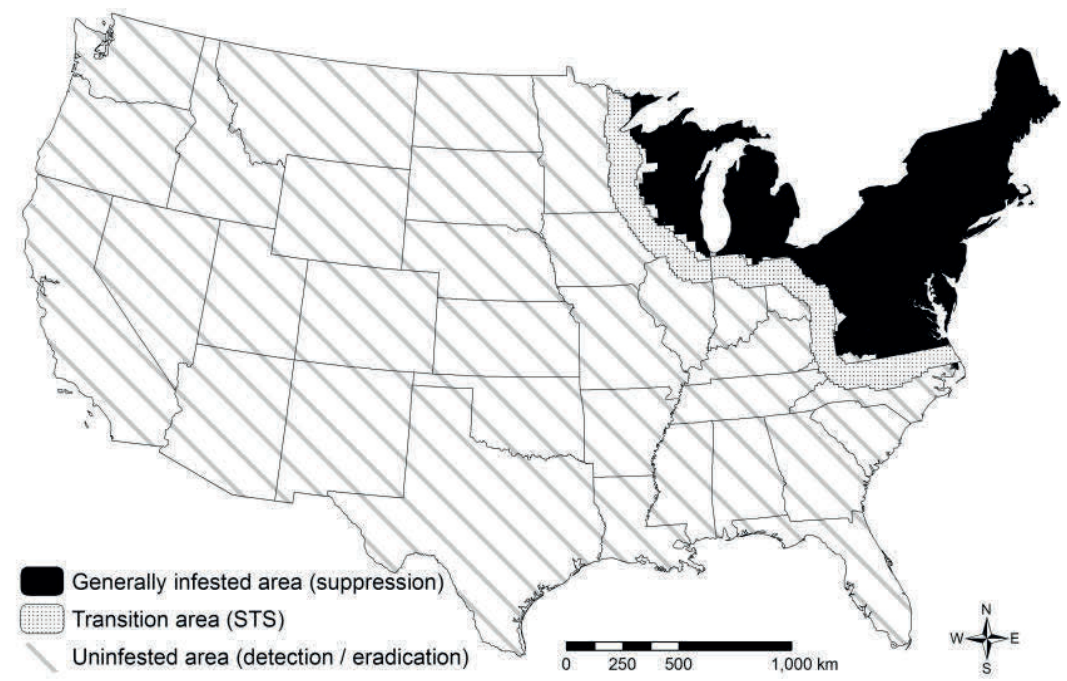

Figure 1. Map showing the spatial extent of invading gypsy moth populations (2017) in the USA and locations of generally infested area, the transition area (STS = "Slow the Spread" programme) and the uninfested area.

\section{DETECTION / ERADICATION}

Gypsy moth egg masses are often laid in cryptic locations and this behaviour leads to egg masses becoming associated with objects, such as cars, lawn furniture and firewood, that are transported during household moves. In the USA, intra-continental household moves are common, and this unfortunately results in gypsy moth egg masses being transported from outbreak areas in the generally infested area into uninfested states. If no action were taken, many of these translocated egg masses would found new populations that would grow and potentially damage forests in these regions. Fortunately, newly founded populations can be efficiently detected using pheromone-baited traps. Female gypsy moths produce a sex attractant, $(+)$ cis-7,8epoxy-2-methyloctadecane ("disparlure"), that was identified in the early 1970's (Bierl et al. 1970) and can be synthesized relatively inexpensively. 
The general strategy of the detection/eradication programme is to detect and eradicate newly founded populations (Fig. 2). The strategy consists of the following steps: (1) regularly deploy an extensive network of traps to detect newly founded populations (Year 1); (2) deploy a dense grid of traps where moths were detected to confirm the persistence of the population and delimit its spatial extent (Year 2); (3) suppress the population below an extinction threshold (Year 3), and (4) deploy a dense grid of traps to confirm eradication or identify areas requiring additional treatment.

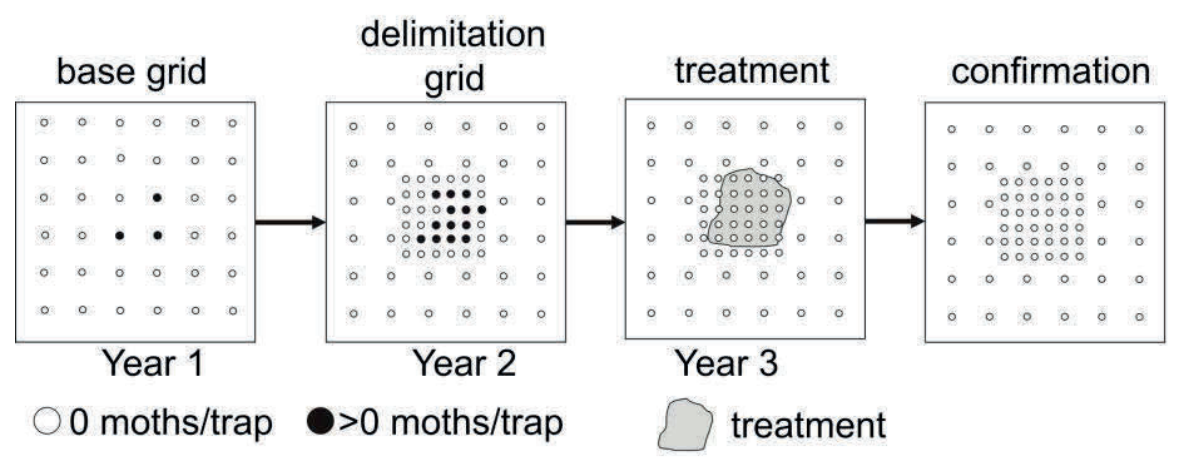

Figure 2. General strategy used in gypsy moth detection/eradication programmes.

Current protocols vary slightly among states, but in most states detection trapping for gypsy moth is conducted once a year in view that this pest has only one generation per year (USDA/APHIS/PPQ 2019). The density of trap deployment varies among land uses with different predicted risks of introduction. For example, affluent residential areas are considered to be high risk and traps are deployed at densities of $\sim 0.4 \mathrm{trap} / \mathrm{km}^{2}$ every other year, but unpopulated forests are considered low risk and traps are deployed at $0.1 \mathrm{trap} / \mathrm{km}^{2}$ in such areas once every 4 years.

The vast majority of traps in base detection trapping capture no males, while capture of one or more males usually triggers delimitation trapping in the next phase (Year 2). This trapping serves both the purpose of delimiting the spatial extent of the invading population but also confirms the persistence of populations. In most cases, capture of one or more males in one year does not result in captures at the same location in the next year; low density populations are prone to extinction due to Allee effects or stochastic dynamics (Liebhold and Bascompte 2003).

The standard trap density in delimitation surveys is $\sim 6$ traps $/ \mathrm{km}^{2}$; delimitation traps are deployed in the area surrounding positive trap capture locations, extending to the nearest negative trap capture locations from the previous generation (USDA/APHIS/PPQ 2019). In addition to delimitation trapping, most states will visually examine a $\sim 1000 \mathrm{~m}^{2}$ vicinity around positive trap captures, searching for egg masses or other life stages. These searches serve two purposes: 1) the presence of immature life stages confirms the existence of a reproducing population, and 2) discovery of immature life stages usually is indicative of the "core" population that then becomes highest priority for treatment. 
Once a population has been detected, found to persist and is delimited, then it is ready for treatment (Year 3). Because low-density gypsy moth populations are strongly affected by Allee effects (mostly arising from mate-location failure [Tobin et al. 2009]), treatments need not kill $100 \%$ of individuals; eradication can be achieved by reducing populations below an Allee threshold and residual populations can be anticipated to decline toward extinction (Liebhold and Bascompte 2003). Most gypsy moth eradication treatments use aerial sprays of Bacillus thuringiensis kurstaki (Btk). Usually at least 2 applications are made in a single year in order to maximize mortality; additional applications are made when there is uncertainty about the timing of susceptible early instars. In very small populations, ground treatments of Btk may be substituted for aerial treatment. Most treatments are applied over relatively small areas (i.e. $<100$ ha) in urban areas so the non-target impacts (e.g. mortality of native Lepidoptera) are minimal. Mating disruption treatments are also quite effective against low-density gypsy moth populations (Thorpe et al. 2006), but they are infrequently used for eradication because mating disruption treatments shut-down trap captures that are used to confirm eradication success. Both types of treatments tend to be effective at eliminating populations in a single year.

Starting in the year of treatment, a grid of traps is deployed to detect residual populations post-treatment. This grid is comparable in density to delimitation grids and can be used to identify areas requiring additional treatments. Small populations are usually successfully eradicated by treatments in a single year, but in large populations it is not unusual to treat additional areas in subsequent years. Eradication success is generally declared after two or more years of no captures (Years 4-5).

With increasing trade between Asian countries and North America over the last decades, there has been an increasing flow of gypsy moth egg masses accidentally transported on ships, containers, bulk steel and cars imported from Asia. Unlike European populations, females from most Asian gypsy moth (AGM) populations are capable of at least some flight (Keena et al. 2008) and females are sometimes attracted in large numbers to brightly-illuminated seaports. Increased flight capabilities in AGM strains is a primary reason why invasions by such populations are anticipated to be more difficult to eradicate and contain. Given this risk, additional traps are deployed in areas adjacent to maritime terminals (both Pacific and Atlantic) and other high-risk locations. All trapped males (including those from the AGM high risk areas and ordinary detection survey traps) are returned to the USDA/APHIS/PPQ Laboratory in Buzzards Bay, Massachusetts where they are subjected to molecular analysis to determine their most likely origin.

Two genetic markers are used to assess the genotype of gypsy moth specimens: the nuclear marker FS1 (Garner and Slavicek 1996) and a mitochondrial marker (Bogdanowicz et al. 1993). Female flight is a trait that is considered to make a population more difficult to contain or eradicate. Consequently, policies for responding to AGM captures are more aggressive in that instead of waiting a year to delimit populations following initial capture (Fig. 2), eradication treatments are generally applied in the same year, directly following initial detection.

Similar practices for detection and eradication of both Asian and European strains of the gypsy moth are implemented in Canada. 


\section{SLOW THE SPREAD (STS)}

As is the case with the spread of many other invading species, gypsy moth range expansion is not a continuous process. Instead, isolated populations sporadically develop ahead of the advancing population front. These isolated populations continuously expand and eventually coalesce with each other and the continuously infested population front (Sharov and Liebhold 1998). This pattern arises from a phenomenon, "stratified diffusion", in which dispersal is comprised of two different types of movement. In the case of the gypsy moth, spatially continuous short-range dispersal results from wind-borne movement of first instars and long-range stochastic dispersal occurs when humans accidentally move egg masses, larvae or pupae (e.g. movement of infested firewood).

In designing the STS programme, it was considered impractical to completely stop gypsy moth spread, but instead the objective shifted to slowing the rate of spread by detecting and suppressing new isolated populations ahead of the advancing front. This is accomplished by deploying a grid of pheromone traps along the transition area in order to detect isolated populations (Fig. 1). These populations are subsequently delimited and treated, much like the strategy used in the detection/eradication programme in the uninfested area (Fig. 2). However, unlike eradication programmes, the objective of treatments is not necessarily extinction of the isolated population, but instead the programme aims to suppress its growth. Population models demonstrate that suppressing these isolated populations ahead of the population front can have a substantial impact on reducing spread even though relatively small areas are treated (Sharov and Liebhold 1998).

The STS programme was initiated as a pilot programme in the states of North Carolina, Virginia, West Virginia and Michigan in 1992 and in 2000 was expanded to the entire population front running from the Atlantic Ocean to the Canadian border (Fig. 1) (favourable gypsy moth host type stops just north of the Canadian border with Minnesota).

The majority of the funding (USD 8 - 10 million / year) for STS comes from the USDA Forest Service, which grants most funds to the STS Foundation, which in turn grants funds to individual state governments to carry out trapping and treatments (Leonard 2007). The STS Foundation is a non-profit organization managed by a representative from each of the 11 states participating in STS. Structuring management of the programme around the Foundation increases partner state ownership of and accountability for the programme, promotes programme management based on biological rather than jurisdictional boundaries and facilitates uniform implementation of protocols, and decision-making.

Expenditure of these funds was justified by a benefit-cost analysis, which demonstrated that the economic benefit of postponing the initiation of gypsy moth impacts and management (e.g. the USDA Forest Service Gypsy Moth Cooperative Suppression Programme described above) expenses vastly exceeds the cost of the STS programme (Leuschner et al. 1996). Roughly half the STS budget is spent on trapping and half on treatments.

Trapping is conducted in a ca. $100 \mathrm{~km}$ band (coincident with the transition area shown in Fig. 1) termed the "action area", in which traps are deployed in a rectangular grid with 2-3 km spacing between traps (Roberts and Ziegler 2007). In a $70 \mathrm{~km}$ band 
located just inside the generally infested area and adjacent to the action area, trapping also takes place in an "evaluation area" in which traps are deployed in a grid with 5$8 \mathrm{~km}$ between traps; trapping data from the evaluation area play a crucial role in measuring reduction in spread rates as well as in locating boundaries for the action area. When base trapping in the action area indicates the location of an isolated population, a delimitation grid is deployed in the next year; delimitation trapping is conducted with traps placed on a grid with 250 to $500 \mathrm{~m}$ between traps. Much like detection/eradication, a delimitation grid is also deployed following treatment in order to evaluate treatment success.

While most treatments in gypsy moth detection/eradication programmes are conducted using Btk, most treatments in STS are conducted using mating disruption (Thorpe et al. 2006). This reflects, in part, the objective of minimizing the overall environmental impact of the STS programme considering that treatments are applied over a relatively large area (Table 1). But also, mating disruption treatments have lower overall costs. Historical data indicate that when applied against low-density populations in the STS programme, mating disruption treatments are equally as effective as Btk applications (Sharov et al. 2002). Occasionally, moderate density gypsy moth populations ( $>\sim 100$ moths / trap) are detected in the STS action area and these populations are usually treated with Btk because of lower efficacy of mating disruption in such higher density populations.

Table 1. Traps deployed, populations treated and treatment areas in the gypsy moth Detection / Eradication and STS programmes 2010-2016

\begin{tabular}{|l|c|c|c|c|c|c|}
\hline \multirow{2}{*}{ Year } & \multicolumn{3}{|c|}{ Detection and Eradication } & \multicolumn{3}{c|}{ Slow the Spread (STS) } \\
\cline { 2 - 7 } & $\begin{array}{c}\text { Traps } \\
\text { deployed }\end{array}$ & $\begin{array}{c}\text { Popula- } \\
\text { tions } \\
\text { treated }\end{array}$ & $\begin{array}{c}\text { Area } \\
\text { treated (ha) }\end{array}$ & $\begin{array}{c}\text { Traps } \\
\text { deployed }\end{array}$ & $\begin{array}{c}\text { Popula- } \\
\text { tions } \\
\text { treated }\end{array}$ & $\begin{array}{c}\text { Area } \\
\text { treated (ha) }\end{array}$ \\
\hline 2010 & 102795 & 2 & 525 & 89950 & 231 & 216125 \\
\hline 2011 & 107646 & 3 & 2340 & 83800 & 221 & 208750 \\
\hline 2012 & 108060 & 2 & 833 & 53900 & 149 & 213414 \\
\hline 2013 & 144925 & 1 & 421 & 47850 & 130 & 164441 \\
\hline 2014 & 112153 & 0 & 755 & 60000 & 138 & 169425 \\
\hline 2015 & 123938 & 2 & 674 & 60000 & 182 & 205561 \\
\hline 2016 & 134151 & 3 & 1484 & 65000 & 176 & 179084 \\
\hline
\end{tabular}

The STS programme represents a highly innovative area-wide integrated pest management programme in many ways. One of the early innovations of the programme was its adoption of GIS technology so that all trap data are georeferenced. But perhaps the most innovative aspect of the programme is its implementation of a highly standardized "decision algorithm" that is applied throughout the programme (Tobin et al. 2004; Tobin and Sharov 2007). The decision algorithm consists of computer code that processes data, mostly in the form of survey trap data, to make decisions on action (trapping and treatment) and to generate output used by STS managers to evaluate the effectiveness of the programme. The decision algorithm was developed, in part, from population models that simulated gypsy moth 
spread and decision-making to optimally reduce spread (Sharov and Liebhold 1998), but the decision algorithm has been continually fine-tuned to increase efficacy and reduce costs without losing efficiency.

The decision algorithm is applied every year to process trapping data from the field. It performs various quality control analyses in order to flag potential data quality problems. The most basic task it performs is the application of several different algorithms to locate potential isolated populations from the base trapping grid. Once these areas are located, the decision algorithm then highlights areas where delimiting trapping should be performed or where treatments are needed.

The other major feature of the decision algorithm is evaluation of programme efficacy. This starts with individual evaluations that are made for each treatment block. But the decision algorithm also measures spread rates along the entire action area in each year. While STS programme managers are constantly monitoring the efficacy of treatments, the ultimate success of the programme is based upon reduction of invasion spread. During the decades prior to the programme's initiation, gypsy moth range expansion averaged $\sim 21 \mathrm{~km} /$ year (Liebhold et al. 1992), but since national implementation of the STS programme in 2000 spread has averaged about 4 $\mathrm{km} /$ year, which is an $80 \%$ reduction and exceeds the programme objective of $50 \%$ reduction in spread.

One of the key features of the decision algorithm is the flow of data and visualization of decision algorithm output (Fig. 3).

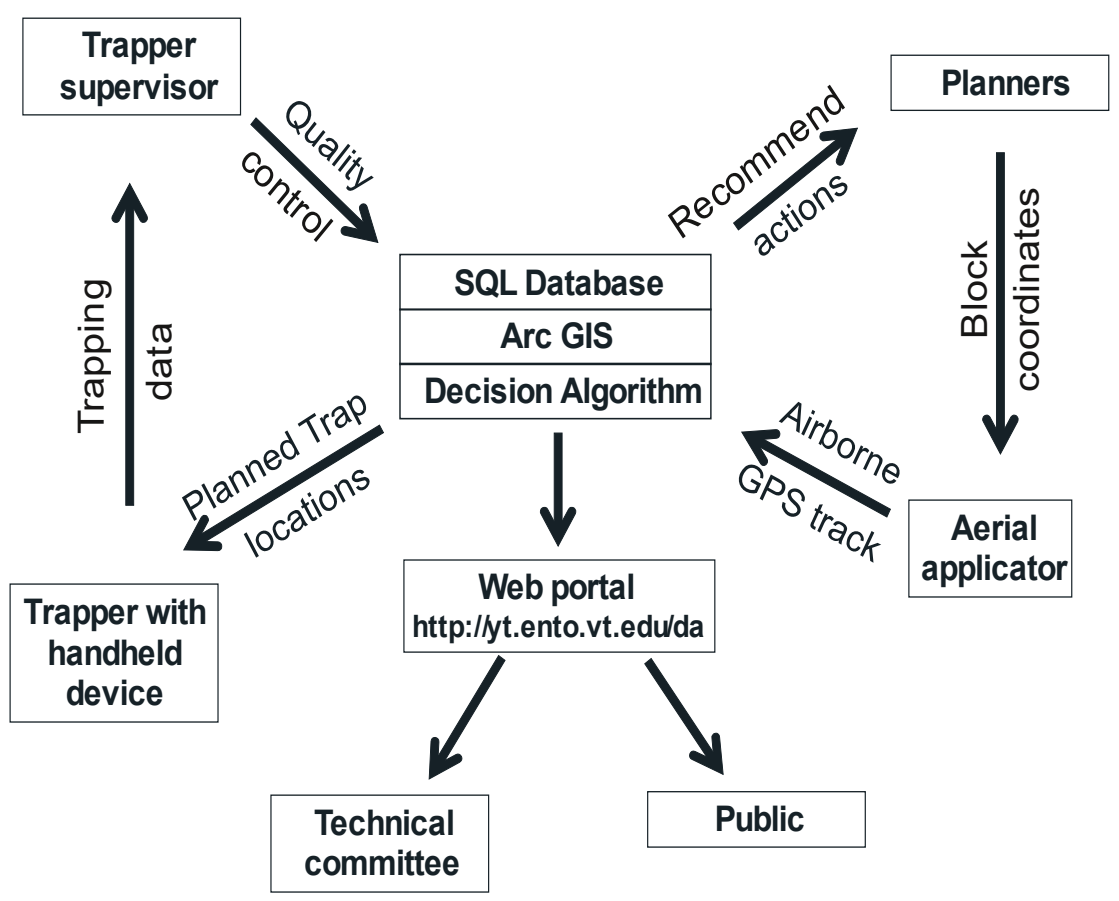

Figure 3. Flow of data and information in the STS programme. "SQL" refers to the structured query language. 
Starting in 1996, the programme adopted the use of handheld GPS units by trappers to guide trap placement and record trap captures, but as technology advanced the GPS units have been replaced by handheld tablets. All of the decision output from the decision algorithm is reviewed each year by state and federal STS planners. For a variety of reasons, planners may decide to over-ride or modify the decision recommended by the decision algorithm. The performance of the programme is closely monitored by STS managers and the STS Technical Committee, and this information is used to adjust the decision algorithm as needed.

Finally, all trap and treatment locations, trap counts, and analyses of programme performance are freely available for viewing on a web portal (STS 2019). This web access makes the programme completely transparent so that any interested members of the public or government agencies can view programme activities.

\section{CONCLUSION}

The gypsy moth is one of the most damaging invasive pests in North America and consequently substantial effort has historically been expended to contain its spread. Over the course of these historical programmes, considerable knowledge has been gained both on understanding how this organism spreads, but also about how to maximize the efficacy of containment efforts. The fact that gypsy moth currently only occupies about $1 / 3$ of its potential range in the USA, despite having become established here for nearly 150 years, reflects the success that has been achieved from these programmes.

A large fraction of the success in limiting the gypsy moth's spread in the USA can be attributed to certain specific technological developments which include the development of an inexpensive yet highly sensitive pheromone trap for this insect, the application of GIS technology and the perfection of various treatment technologies for eradication or suppression of high- and low-density populations.

With increasing globalization, the problem of biological invasions continues to grow as thousands of species are moved around the globe, often causing catastrophic impacts. Given this trend, there is increasing need for effective strategies not only for eradication of newly established populations, but also to contain populations when eradication is not feasible. Technological developments that have facilitated the highly successful area-wide programmes for limiting the spread of the gypsy moth serve as models for management of other invading organisms. Many components of these programmes can be readily applied in other containment systems and should help limit the impacts of invading organisms in the future.

\section{REFERENCES}

Bierl, B. A., M. Beroza, and C. W. Collier. 1970. Potent sex attractant of the gypsy moth: Its isolation, identification, and synthesis. Science 170(3953): 87-89.

Bogdanowicz, S. M., W. E. Wallner, J. Bell, T. M. Odell, and R. G. Harrison 1993. Asian gypsy moths (Lepidoptera: Lymantriidae) in North America: Evidence from molecular data. Annals of the Entomological Society of America 86: 710-715.

Garner, K. J., and J. M. Slavicek. 1996. Identification and characterization of a RAPD-PCR marker for distinguishing Asian and North American gypsy moths. Insect Molecular Biology 5: 81-91. 
Giese, R. L., and M. L. Schneider. 1979. Cartographic comparisons of Eurasian gypsy moth distribution (Lymantria dispar L.; Lepidoptera: Lymantriidae). Entomological News 90: 1-16.

Johnson, D. M., A. M Liebhold, O. N. Bjørnstad, and M. L. McManus. 2005. Circumpolar variation in periodicity and synchrony among gypsy moth populations. Journal of Animal Ecology 74: 882892.

Keena, M. A., M. J. Côté, P. S. Grinberg, and W. E. Wallner. 2008. World distribution of female flight and genetic variation in Lymantria dispar (Lepidoptera: Lymantriidae). Environmental Entomology 37: 636-649.

Leonard, D. S. 2007. Chapter 7. Project organization, planning, and operations. pp. 91-98. In P. C. Tobin, and L. M. Blackburn (eds.), Slow the Spread: A national program to manage the gypsy moth. USDA Forest Service Northern Research Station General Technical Report NRS-6. Morgantown, West Virginia, USA

Leuschner, W. A., J. A. Young, S. A. Waldon, and F. W. Ravlin. 1996. Potential benefits of slowing the gypsy moth's spread. Southern Journal of Applied Forestry 20: 65-73.

Liebhold, A. M. and J. Bascompte. 2003. The Allee effect, stochastic dynamics and the eradication of alien species. Ecology Letters 6: 133-140.

Liebhold, A., V. Mastro, and P. W. Schaefer. 1989. Learning from the legacy of Leopold Trouvelot. Bulletin of the Entomological Society of America 35: 20-22.

Liebhold, A. M., J. Halverson, and G. Elmes. 1992. Quantitative analysis of the invasion of gypsy moth in North America. Journal of Biogeography 19: 513-520.

McManus, M. L. 2007. Chapter 1. In the beginning: Gypsy moth in the United States, pp. 3-13. In P.C. Tobin, and L. M. Blackburn (eds.), Slow the Spread: A national program to manage the gypsy moth. USDA Forest Service Northern Research Station General Technical Report NRS-6. Morgantown, West Virginia, USA.

Morin, R. S., and A. M. Liebhold. 2016. Invasive forest defoliator contributes to the impending downward trend of oak dominance in eastern North America. Forestry 89: 284-289.

Morin, R. S., A. M. Liebhold, E. R. Luzader, A. J. Lister, K. W. Gottschalk, and D. B. Twardus. 2004. Mapping host-species abundance of three major exotic forest pests. USDA Forest Service Northeastern Research Station Research Paper NE-726. Morgantown, West Virginia, USA.

Roberts, E. A., and A. H. Ziegler. 2007. Chapter 3. Gypsy moth population monitoring and data collection, pp. 33-46. In P.C. Tobin, and L. M. Blackburn (eds.), Slow the Spread: A national program to manage the gypsy moth. USDA Forest Service Northern Research Station General Technical Report NRS-6. Morgantown, West Virginia, USA.

Sharov, A. A., and A. M. Liebhold. 1998. Model of slowing the spread of gypsy moth (Lepidoptera: Lymantriidae) with a barrier zone. Ecological Applications 8: 1170-1179.

Sharov, A. A., D. S. Leonard, A. M. Liebhold, and N. S. Clemens. 2002. Evaluation of preventive treatments in low-density gypsy moth populations. Journal of Economic Entomology 95: 1205-1215.

(STS) Slow the Spread. 2019. Slow the Spread Foundation, Inc.

Thorpe, K., R. Reardon, K. Tcheslavskaia, D. Leonard, and V. Mastro. 2006. A review of the use of mating disruption to manage gypsy moth, Lymantria dispar (L.). Forest Health Technology Enterprise Team 2006-13. USDA Forest Service, Washington, DC, USA.

Tobin, P. C., and A. A. Sharov. 2007. Chapter 4. The decision algorithm: Selection of and recommendation for potential problem areas, pp. 47-6. In P.C. Tobin, and L. M. Blackburn (eds.), Slow the Spread: A national program to manage the gypsy moth. USDA Forest Service Northern Research Station General Technical Report NRS-6. Morgantown, West Virginia, USA.

Tobin, P. C., A. A. Sharov, A. M. Liebhold, D. S. Leonard, E. A. Roberts, and M. R. Learn. 2004. Management of the gypsy moth through a decision algorithm under the STS project. American Entomologist 50: 200-209.

Tobin, P. C., C. Robinet, D. M. Johnson, S. L. Whitmire, O. N. Bjørnstad, and A. M. Liebhold. 2009. The role of Allee effects in gypsy moth (Lymantria dispar (L.)) invasions. Population Ecology 51: 373-384.

(USDA/APHIS/PPQ) United States Department of Agriculture/Animal and Plant Health Inspection Service/Plant Protection and Quarantine. 2019. Gypsy moth program manual. Second edition.

(USDA/USFS) United States Department of Agriculture/United States Forest Service. 2017. Gypsy moth digest. Northeastern Area State and Private Forestry. 